\title{
Qualidade de hortaliças comercializadas no noroeste do Paraná, Brasil
}

\author{
LUCIA MORAIS FALAVIGNA*, CARLA BOCHNIA RODRIGUES DE FREITAS*, \\ GISELY CARDOSO DE MELO*, LETÍCIA NISHI*, SILVANA MARQUES DE ARAÚJO* \\ e ANA LUCIA FALAVIGNA-GUILHERME*
}

\section{QUALITY OF GREEN VEGETABLES MARKETED IN THE NORTHWEST OF PARANÁ, BRAZIL}

\begin{abstract}
This work had the objective of performing a parasitological evaluation of fresh vegetables colleted from production places and free markets of Maringá, Paraná. From July/2002 to July/2004, 66 samples were collected in 13 smallholdings and 181 samples in 17 free markets. Heads of lettuce (varieties flat, curly and American), watercress and rocket salad, picked up randomly and in triplicate, were submitted to Oliveira \& Germano's and Kynioun staining techniques and to the research of total and thermotolerant coliforms. The total index of parasitism of the vegetables of free markets (63\%) and smallholdings $(71.1 \%)$ didn't differ statistically. The fresh vegetables from smallholdings have shown more protozoa than (10/47) that from the free markets (19/114). Rhabditoidea larvae and Ancylostomatoidea eggs were equally distributed in the fresh vegetables of both places. Parasitic forms of other species were also found. All the curly lettuce samples collected in the smallholdings presented total and thermotolerant bacteria index incompatible with the human consumption. The difficult in doing laboratorial diagnose at the genre and specie level of the human parasites in fresh vegetables and the sanitary surveillance challenges in the obtaining of good quality products were discussed.
\end{abstract}

Key words: fresh vegetables quality, protozoa, helminthes, producers, free markets.

\section{INTRODUÇÃO}

A infecção alimentar por helmintos e protozoários veiculados pela ingestão de hortaliças consumidas cruas tem aumentado. Este aumento é resultante de vários fatores, destacando a expansão do comércio internacional de gêneros alimentícios ${ }^{1}$, a mudanças nos hábitos alimentares, o consumo extradomiciliar de refeições rápidas e pré-preparadas $^{2}$ e o crescimento populacional desordenado nos grandes centros urbanos. A água contaminada por matéria fecal de origem humana $^{3,4}$ utilizada na irrigação de hortas ${ }^{3,5,6}$ e a contaminação de alimentos por manipuladores

\section{Correspondência}

Profa. Dra. Ana Lucia Falavigna-Guilherme.

Laboratório de Parasitologia Ambiental e de Alimentos, Departamento de AnálisesClinicas, Universidade Estadual de Maringá. Brasil.

Av. Colombo 5790, Bloco I-90, sala 11, 87020-900, Maringá, Paraná.

E-mail: alfguilherme@uem.br; Fone: (44) 261-4877. 
infectados também podem ser apontados como causas de contaminação de hortaliças ${ }^{7}$. A pesquisa de parasitas de interesse humano em hortaliças é de grande importância na área de saúde pública especialmente considerando as etapas de produção, armazenagem, transporte, manuseio e comercialização desses produtos ${ }^{8}$.

As amostras de diferentes hortaliças consumidas cruas da Feira do Produtor de Maringá, Paraná, região sul do Brasil, apresentaram-se significativamente contaminadas por enteroparasitas ${ }^{9}$. De acordo com o $\mathrm{IBGE}^{10}$, está ocorrendo um aumento no consumo de verduras, frutas e legumes pela população, sobretudo da região sul e sudeste do Brasil, elevando o risco de ingestão de estruturas parasitárias transmitidas por estes alimentos quando ingeridos crus. Com base nestes dados, o objetivo deste trabalho foi avaliar parasitologicamente a qualidade de hortaliças consumidas cruas provenientes de locais de produção e feiras livres comercializadas no município de Maringá, Paraná.

\section{MATERIAL E MÉTODOS}

Locais de coleta: Foram consideradas como locais de coletas 22 feiras semanais existentes em diferentes pontos da cidade de Maringá e chácaras da periferia dos municípios de Maringá e Sarandi, estado do Paraná, que abastecem estas feiras. A localização das feiras livres existentes na cidade e aquelas em que foi realizadas a investigação parasitológica* foran:

1.- Avenida Sao Judas Tadeu. 2.- Rua Ivens Pacheco. 3.- Avenida Alziro Zarur. 4.- Avenida Mandacaru. 5.- Rua Mandaguari. 6.- Rua Córdoba 7.- Rua Uruguai. 8 Rua Miguel Ferreira. 9.- Rua Francisco Bulla 10.- Rua Caracas 11.- Rua São Cristóvão 12.- Praça Emiliano Perneta 13.- Avenida Mauá 14.- Avenida Prudente de Moraes 15.- Rua José Clemente 16.- Rua Ermelino Leão 17.- Rua Nassib Had 18 Avenida Humait 19.- Avenida Cerro Azul 20.- Avenida Riachuelo 21.- Praça Todos os Santos 22.- Rua Azaléia *Feiras livres em que foram realizados a coleta e análise parasitológica das hortaliças.As chácaras amostradas eram de pequenos produtores e se localizavam no entorno da zona urbana e em fundo de vales. As coletas foram realizadas de julho de 2002 a julho de 2004 .

\section{Amostras de hortaliças}

As amostras de alface (Lactuca sativa) variedades lisa, crespa e americana, agrião (Nasturtium officinale) e rúcula (Eruca sativa) foram coletadas em triplicata, aleatoriamente. Nas feiras livres, as amostras de hortaliças foram amostradas de $90 \%$ das barracas que comercializavam estes produtos, em todos os dias da semana.

As hortaliças foram acondicionadas individualmente em sacos de polietileno descartáveis de primeiro uso, sem contato manual, e encaminhadas ao Laboratório de Parasitologia Ambiental e de Alimentos da Universidade Estadual de Maringá para a análise. Foram determinados como unidade amostral para a alface, pés inteiros, independentes do peso e tamanho. Para os demais vegetais, o maço constituiu a unidade amostral.

Análise das amostras: As amostras foram identificadas e as folhas foram separadas uma a uma, com a utilização de luvas cirúrgicas, desprezando-se as deterioradas e os talos. Para a lavagem, foram utilizados $250 \mathrm{ml}$ de solução de extram MA 02 em água destilada ${ }^{11}$. O sedimento obtido, após repouso de 24 horas foi analisado em triplicata, corada com lugol, para a pesquisa de ovos ou larvas de helmintos. O restante do sedimento foi submetido ao método de centrífugoflutuação em sulfato de zinco ${ }^{12}$ para a pesquisa de cistos de protozoários e ao método de Kynioun modificado $^{13}$ para a pesquisa de oocistos de Cryptosporidium sp. e de Cyclospora cayetanensis.

Em 30\% das alfaces crespas coletadas de chácaras foi realizada a análise bacteriológica pesquisando bactérias do grupo de coliformes totais e termotolerantes ${ }^{14}$. Para tanto foram utilizados $100 \mathrm{ml}$ do líquido obtido pela lavagem das hortaliças com água estéril.

Análise Estatística: O índice de parasitismo das hortaliças amostradas em chácaras e feiras foi comparado pelo teste não paramétrico de Mann-Whitney, com 5,0\% de significância. O teste de Kruskal Wallis foi utilizado para comparar a contaminação entre as variedades de hortaliças de cada local de coleta. O teste $t$ foi empregado para comparar o número total de protozoários e helmintos encontrado de hortaliças de chácaras e feiras.

\section{RESULTADOS}

Foram avaliadas $17(77,3 \%)$ das 22 feiras existentes no município de Maringá. A prevalência de protozoários e helmintos não diferiu entre as 
Tabela 1.Avaliação parasitológica de hortaliças provenientes de feiras livres do município de Maringá, Pr, no período de julho de 2002 a julho de 2003

\begin{tabular}{|c|c|c|c|c|c|c|}
\hline Formas encontradas & $\begin{array}{c}\text { Alface } \\
\text { americana }\end{array}$ & $\begin{array}{l}\text { Alface } \\
\text { crespa }\end{array}$ & $\begin{array}{l}\text { Alface } \\
\text { lisa }\end{array}$ & Agrião & Rúcula & Total \\
\hline Larvas de Rhabdiasoidea & 13 & 16 & 16 & 2 & 4 & 51 \\
\hline Larvas de Ancylostomatoidea & 7 & 6 & 4 & 5 & 2 & 24 \\
\hline Ovos de Ancylostomatoidea & 22 & 26 & 18 & 17 & 5 & 88 \\
\hline Ovos de Capillaria sp. & - & - & - & 1 & - & 1 \\
\hline Ovos de Trichostrongylus & - & - & - & - & 1 & 1 \\
\hline Cistos de Amoebidae & 1 & 1 & - & - & 2 & 4 \\
\hline Cistos de Iodamoeba & - & - & 1 & - & 1 & 2 \\
\hline Cistos de Entamoeba sp. & - & 1 & 2 & - & - & 3 \\
\hline Cistos de Endolimax nana & - & - & 1 & - & - & 1 \\
\hline Oocistos Toxoplasma-like & 2 & 2 & - & - & - & 4 \\
\hline Oocistos de Isospora belli & - & 1 & - & - & - & 1 \\
\hline Oocistos não esporulado de coccídio & 1 & 1 & - & - & - & 2 \\
\hline Oocistos de Sarcocystis sp. & - & 1 & - & - & - & 1 \\
\hline Oocistos de Eimeria sp. & - & - & 1 & - & - & 1 \\
\hline Total de amostras analisadas & 49 & 51 & 38 & 22 & 21 & 181 \\
\hline Total de amostras parasitadas & 27 & 36 & 29 & 15 & 07 & 114 \\
\hline Porcentagem de amostras parasitadas & $55,0 \%$ & $70,0 \%$ & $76,0 \%$ & $68,0 \%$ & $33,0 \%$ & $63,0 \%$ \\
\hline
\end{tabular}

* não foi possível a identificação até espécie

Tabela 2. Avaliação parasitológica de hortaliças provenientes de chácaras do município de Maringá, Pr, no período de julho de 2003 a julho de 2004

\begin{tabular}{lrrrrrr}
\hline Formas encontradas & $\begin{array}{c}\text { Alface } \\
\text { americana }\end{array}$ & $\begin{array}{c}\text { Alface } \\
\text { crespa }\end{array}$ & $\begin{array}{c}\text { Alface } \\
\text { lisa }\end{array}$ & Agrião & Rúcula & Total \\
\hline Larvas de Rhabdiasoidea & - & 01 & - & - & - & 01 \\
Larvas de Ancylostomatoidea & 04 & 06 & 01 & - & - & 11 \\
Ovos de Ancylostomatoidea & 09 & 14 & 04 & 02 & 11 & 40 \\
Ovos de Toxocara sp & 01 & - & 03 & - & - & 04 \\
Ovos de Acantocephala & - & - & 01 & - & - & 01 \\
Cistos de Ameba* & 02 & 01 & 01 & - & - & 04 \\
Oocistos deIsospora rivolta & 01 & 01 & - & - & - & 02 \\
Oocistos de coccídio & 01 & - & 01 & - & - & 02 \\
Oocistos de Eimeria sp & 02 & - & - & - & - & 02 \\
Total de amostras analisadas & 16 & 18 & 14 & 04 & 14 & 66 \\
Total de amostras parasitadas & 13 & 14 & 07 & 02 & 11 & 47 \\
Porcentagem de amostras parasitadas & $81,0 \%$ & $78,0 \%$ & $50,0 \%$ & $50,0 \%$ & $78,0 \%$ & $71,1 \%$ \\
\hline
\end{tabular}

* não foi possível a identificação até espécie

feiras livres pesquisadas, independente de sua localização. Os feirantes expunham suas hortaliças em várias feiras realizadas ao longo da semana até o esgotamento do estoque. Das 181 amostras de hortaliças analisadas, 114 (63,0\%) encontravam-se parasitadas por protozoários e/ ou helmintos. A alface lisa, a alface crespa e o agrião, foram as hortaliças mais contaminadas (Tabela 1). As formas prevalentes foram ovos de Ancylostomatoidea, larvas de Rhabditoidea e de Ancylostomatoidea, correspondendo a 77\%, $45 \%$ e $21 \%$, respectivamente (Tabela 1). Cistos de amebas e oocistos de coccídios ocorreram com a mesma freqüência, destacando-se Amoebidae e Toxoplasma-like (Tabela 1).

Foram investigadas 13 chácaras, oito no município de Maringá e cinco no município de Sarandi. Das 66 amostras analisadas, 47 (71,1\%) 
foram positivas para algum protozoário e/ou helminto (Tabela 2). Todas as chácaras apresentaram uma ou mais hortaliças parasitadas. As hortaliças mais contaminadas foram: alface americana, alface crespa e rúcula (Tabela 2). Ovos e larvas de Ancylostomatoidea foram as formas parasitas mais encontradas (Tabela 2). Cistos e oocistos de protozoários foram também observados em menor quantidade (Tabela 2).

$\mathrm{O}$ índice total de parasitismo das hortaliças de feiras $(63 \%)$ e chácaras $(71,1 \%)$ não diferiu estatisticamente ( $p=0,094893)$. A comparação entre hortaliças da mesma variedade provenientes de diferentes locais evidenciou que a alface americana coletada nas chácaras $(81 \%)$ estava mais contaminada $(\mathrm{p}=0,000231)$ que a coletada em feiras $(55 \%)$.

As hortaliças das chácaras estavam mais parasitadas por protozoários $(10 / 47)(\mathrm{p}=$ $0,02697)$ que as da feira (19/114). Não foi observada diferença entre o número de hortaliças de chácaras (57/47) e feiras (167/114) contaminadas por helmintos $(\mathrm{p}=0,876558)$. Da mesma forma, foi verificado que larvas da superfamília Rhabditoidea $(\mathrm{p}=0,094411)$ e ovos da superfamília Ancylostomatoidea $(\mathrm{p}=0,258660)$ estavam igualmente distribuídos nas hortaliças de ambos os locais.

A pesquisa para Cryptosporidium spp. e $C$. cayetanensis foi negativa em todas as amostras analisadas.

Todas as amostras de alface crespa coletadas nas chácaras revelaram a presença de bactérias totais e fecais (termotolerantes) em índices não compatíveis com o consumo humano.

\section{DISCUSSÃO}

Os resultados apresentados neste trabalho são expressivos uma vez que foram pesquisadas a quase totalidade das feiras livres de Maringá. Deve ser ressaltado que a cidade de Maringá é pólo distribuidor de mercadorias para o Paraná, parte do Mato Grosso do Sul e está envolvida no trânsito comercial do Mercosul ${ }^{15,16}$. Não foi observada diferença da prevalência de protozoários e/ou helmintos nas feiras livres analisadas, mesmo quando localizadas em bairros de menor poder aquisitivo. Estes resultados discordaram dos outros que verificaram maior contaminação das hortaliças comercializadas em supermercados da zona norte do Rio de Janeiro que as comerciali- zadas na zona sul, região com população de maior poder aquisitivo ${ }^{17}$.

O índice total de parasitismo não diferiu estatisticamente quando hortaliças provenientes das feiras foram comparadas com as amostras das chácaras. A contaminação das hortaliças por parasitas pode se dar durante o cultivo do vegetal, etapa importante para o controle de parasitoses ${ }^{17}$. A localização das chácaras, no entorno da zona urbana e em fundo de vales, pode ter facilitado a contaminação das hortaliças devido a detritos trazidos pela água das chuvas, a contaminação do solo e de mananciais aquáticos.

No entanto, as hortaliças das chácaras estavam mais contaminadas por protozoários que as das feiras. Esses dados podem ser explicados pelas observações que citam que a rotina de interrupção da irrigação de hortaliças um mês antes da colheita diminui drasticamente a probabilidade do encontro de parasitas nestes produtos ${ }^{18}$. Outro aspecto a ser destacado é que os feirantes relataram a prática de imergir as hortaliças em água antes da exposição do produto para melhorar sua aparência. Com vistas à prevenção, esta prática pode ser entendida como um elo importante para o controle considerando a educação sanitária dos feirantes.

Com relação aos helmintos, as práticas acima mencionadas, não foram suficientes para a diminuição de seus índices. Estes dados estão de acordo com investigadores que observaram a manutenção da contaminação por larvas de Strongyloides stercoralis de hortaliças in natura, após sua lavagem ${ }^{4}$. A estrutura e tamanho dos helmintos podem ter dificultado sua remoção das hortaliças ${ }^{4}$, sendo este uma lacuna a ser abordada em estudos futuros.

As formas evolutivas de helmintos predominaram tanto nas feiras quanto nas chácaras. Trabalhos utilizando metodologia semelhante também relataram a presença de grande número de ovos e larvas de ancilostomídeos nas hortaliças ${ }^{9,19}$. Contudo, deve ser mencionada a dificuldade em diagnosticar laboratorialmente gênero e espécie de estruturas como ovos e larvas de Ancylostomatoidea e Rhabdiasoidea, devido à semelhança morfológica que apresentam quando visualizados por microscopia óptica. Numerosas espécies destas superfamílias são parasitas de outros animais e seres de vida livre e não representam perigo a saúde humana. Entretanto, deve ser considerado que alguns nematóides de 
vida livre, como Caenorhabditis elegans, podem desempenhar papel importante na transmissão de patógenos como Cryptosporidim parvum ${ }^{20}$.

A alface é uma das hortaliças mais produzida e consumida no sul do Brasil. Tanto nas feiras quanto nas chácaras a alface foi a hortaliça mais contaminada por ovos e larvas de helmintos. Esses dados podem ser explicados uma vez que as folhas múltiplas e a estrutura compacta permitem maior fixação das formas parasitas ${ }^{9}$. A presença de coliformes fecais na água de lavagem da alface crespa indicou contaminação fecal. Embora exista resolução do Conselho Nacional de Meio Ambiente ${ }^{21-23}$ estabelecendo que águas utilizadas na irrigação de hortaliças ingeridas cruas devem ser isentas de contaminação fecal humana, a avaliação de hortaliças não é uma preocupação incluída entre os protocolos de qualidade destes alimentos. A investigação e atuação constantes de órgãos de vigilância sanitária nos locais de produção e de distribuição de hortaliças e o desenvolvimento de novas metodologias para avaliação parasitológica são pontos indispensáveis na obtenção de produtos de boa qualidade.

O controle parasitológico de hortaliças é um grande desafio, particularmente quando verificase a inclusão cada vez maior de hortaliças na dieta da população mundial, a globalização na distribuição de alimentos, a expansão nos serviços de alimentos comercializados e o surgimento de novos métodos de produção de alimentos em larga escala sem a devida apropriação de conhecimento científico e tecnológico para o diagnóstico de contaminantes pelos órgãos responsáveis pela vigilância epidemiológica. Ainda, fatores envolvidos na disseminação de parasitoses propiciam o aparecimento de novos agentes infecciosos ou a reemergência de agentes resistentes a medicamentos. Tudo isto leva à discussão de métodos alternativos de controle que passam obrigatoriamente por um processo educativo dos usuários, seja consumidor ou produtor do alimento, interferindo em hábitos culturais e na macro e macroeconomia.

\section{RESUMO}

O objetivo deste trabalho foi avaliar parasitologicamente a qualidade de hortaliças consumidas cruas provenientes de locais de produção e de feiras livres do município de Maringá, Paraná. De julho/2002 a julho/2004, foram coletadas 66 amostras de hortaliças em 13 chácaras e 181 amostras em 17 feiras livres. Pés de alface (variedades lisa, crespa e americana), maços de agrião e rúcula, recolhidos aleatoriamente e em triplicata foram submetidos às técnicas de Oliveira \& Germano, Kynioun e à pesquisa de coliformes totais e termotolerantes. O índice total de parasitismo das hortaliças de feiras $(63 \%)$ e chácaras $(71,1 \%)$ não diferiu estatisticamente. As hortaliças das chácaras mostraram-se mais parasitadas por protozoários (10/47) que as das feiras (19/114). Larvas de Rhabditoidea e ovos de Ancylostomatoidea encontravam-se igualmente distribuídos nas hortaliças de ambos os locais. Formas parasitárias de outras espécies foram também encontradas. Todas as amostras de alface crespa coletadas nas chácaras estavam contaminadas por bactérias totais e termotolerantes em índices não compatíveis com o consumo humano. São discutidos ainda a dificuldade em se diagnosticar laboratorialmente gênero e espécie de parasitas de interesse humano observados em hortaliças e os desafios da vigilância epidemiológica na busca de boa qualidade para hortaliças ingeridas cruas.

Palavras chave: qualidade de hortaliças, protozoários, helmintos, produtores, feiras livres.

\section{REFERÊNCIAS}

1.- KÄFERSTEIN F, ABDUSSALAM M. Food safety in the 21st century. Bull. WHO, 1999; 77: 347-51.

2.- CAPUANO D M, OKINO M H T, BETTINI M J C B, et al. Busca ativa de teníase e de outras enteropa-rasitoses em manipuladores de alimentos no município de Ribeirão Preto, SP, Brasil. Rev Inst Adolfo Lutz 2002; 61: 33-8.

3.- MARZOCHI M C A. Estudo dos fatores envolvidos na disseminação dos enteroparasitas. II-Estudo da contaminação de verduras e solo de hortas na cidade de Ribeirão Preto, São Paulo, Brasil. Rev Inst Med Trop São Paulo 1977; 19: 148-1556.

4.- SILVA L M P S, OLIVEIRA S M, MILMAM M H S A, et al. Detecção de formas parasitárias na água e nas hortaliças consumidas em comunidades escolares de Sorocaba, São Paulo, Brasil. Rev Soc Bras Med Trop 2001; 34: 479-82.

5.- FARIA J A S, SILVA A A, FARIA M S C, et al. Estudo da poluição das águas de irrigação de hortas por cistos e ovos de enteroparasitas. Rev Baiana Saúde Pub 19861987; 13/14: 141-4.

6.- PATTOLI D, PALIN V. Enteroparasitas de águas de irrigação de hortas que abastecem o município de São Paulo. Revista Paulista de Medicina 1966; 68: 241.

7.- CARVALHO J B, NASCIMENTO E R, RIBEIRO V R, et al. Presença de ovos de helmintos em hortaliças fertilizadas com lodo de lagoa de estabilização. Rev Bras Análises Clínicas 2003; 35: 101-3. 
8.- COELHO L M P S, OLIVEIRA S M, MILMAN M H S A, et al. Detecção de formas transmissíveis de enteroparasitas na água e nas hortaliças consumidas em comunidades escolares de Sorocaba, São Paulo, Brasil. Rev Soc Bras Med Trop 2001; 34: 479-82.

9.- FALAVIGNA-GUILHERME A L, ARAÚJO S M, FALAVIGNA D L M, et al. Prevalência de enteroparasitas em horticultores e hortaliças da Feira do produtor de Maringá. Brasil. Revista Sociedade Brasileira Medicina Tropical São Paulo 1999; 32(4): 405-11.

10.- INSTITUTO BRASILEIRO DE GEOGRAFIA E ESTATÍSTICA (IBGE). Pesquisa de orçamentos familiares 2002-2003. Análise da disponibilidade domiciliar de alimentos e do estado nutricional no Brasil. Rio de Janeiro, 2004. 76p. Disponível em www.ibge.gov.br/home/estatistica/população/ condicaodevida/pdf/2002analise/pdf2002.analisepdf. Acessado em 11/01/2005.

11.- OLIVEIRA C A F, GERMANO P M L. Estudo da ocorrência de enteroparasitas em hortaliças comercializadas na região metropolitana de São Paulo, SP, Brasil. I- Pesquisa de helmintos. Revista de Saúde Pública 1992; 26: 283-9.

12.- PESSOA S R, MARTINS A V. Pessôa Parasitologia Médica. 11. ed. Rio de Janeiro: Guanabara Koogan, 1982.

13.- DE CARLI G A. Parasitologia Clínica: seleção de métodos e técnicas de laboratório para o diagnóstico de parasitoses humanas. São Paulo: Editora Atheneu, 2001. 810 pp.

14.- CLESCERI L S, GREENBERG A E, EATON A D. Standard methods for the examination of water and wastewater. 20. ed. 1998. part. 9000- Microbiological Examination. P. 53-54.

15.- CONSELHODE DESENVOLVIMENTOECONÔMICO DE MARINGÁ (CODEM). Histórico. Disponível em www.codem.org.br/codem/?action=historico. Acessado em 13/10/2004.

16.- SECRETARIA DA INDÚSTRIA E COMÉRCIO DO PARANÁ. Relatório de Atividades 2003. Disponível em http://www.pr.gov.br/seim/10_relatorio2003.shtml. Acessado em 13/10/2004.

17.- SILVA J P, MARZOCHI MCA, CAMILO-COURA L, et al. Estudo da Contaminação por enteroparasitas em hortaliças comercializadas nos supermercados da cidade do Rio de Janeiro. Revista da Sociedade Brasileira de Medicina Tropical São Paulo 1995; 28: 237-41.

18.- BEUCHAT L R, RYU J H. Produce handling and processing pratices. Emerg Infect Dis 1997; 3: 459-65.

19.- TAKAYANAGUI O M, FEBRÔNIO L H P, BERGAMINI A M M, et al. Fiscalização de hortas produtoras de verduras do município de Ribeirão Preto, SP. Revista da Sociedade Brasileira de Medicina Tropical, São Paulo 2000; 33(2): 169-74.

20.- HUAMANCHAY O, GENZLINGER L, IGLESIAS M, ORTEGA Y R. Ingestion of Cryptosporidium oocysts by Caenorhabditis elegans. J Parasitol 2004; 90: 1176-8.

21.- CONSELHO NACIONAL DE MEIO AMBIENTE (CONAMA). Resolução Federal n ${ }^{\circ} 20$ de 18.06.86.

22.- BASTOS R K X, NASCIMENTO L E, BEVILAQUA P D, COSTA S S. Implementando a Portaria 1.469: uma breve análise de custos de programas de controle da qualidade da água. Trabalho completo. In: Exposição de Experiências Municipais em Saneamento, 7, Brasília: ASSEMAE, 2003. v.cdroom.

23.- BASTOS R KX. Qualidade microbiológica da água para a irrigação de hortaliças. Trabalho completo. In: Contribuições do setor saúde: Resolução CONAMA n ${ }^{\circ}$ 20/1986. Disponível em http://www.mma.gov.br/port/ conama/processos/C4297E2D/SintesePropostas.doc. Acessado em 13/10/2004. 